\title{
Poly(lactic acid)/Poly(ethylene glycol) Polymer Nanocomposites: Effects of Graphene Nanoplatelets
}

\author{
Buong Woei Chieng ${ }^{1, *}$, Nor Azowa Ibrahim ${ }^{1, *}$, Wan Md Zin Wan Yunus ${ }^{2}$ and \\ Mohd Zobir Hussein ${ }^{3}$
}

1 Department of Chemistry, Faculty of Science, Universiti Putra Malaysia, UPM Serdang, Selangor 43400, Malaysia

2 Department of Chemistry, Center for Defence Foundation Studies, National Defence University of Malaysia, Kuala Lumpur 57000, Malaysia; E-Mail: wanmdzin@upnm.edu.my

3 Institute of Advanced Technology, Universiti Putra Malaysia, UPM Serdang, Selangor 43400, Malaysia; E-Mail: mzobir@upm.edu.my

* Authors to whom correspondence should be addressed; E-Mails: chieng891@gmail.com (B.W.C.); norazowa@upm.edu.my (N.A.I.); Tel.: +603-8946-6602 (B.W.C.); +603-8946-6802 (N.A.I.); Fax: +603-8943-2508 (B.W.C.); +603-8943-5380 (N.A.I.).

Received: 10 November 2013; in revised form: 10 December 2013 / Accepted: 13 December 2013 / Published: 31 December 2013

\begin{abstract}
Graphene nanoplatelets (xGnP) were investigated as a novel nano-reinforcement filler in poly(lactic acid)(PLA)/poly(ethylene glycol)(PEG) blends by the melt blending method. PLA was first plasticized by PEG in order to improve its flexibility and thereby overcome its problem of brittleness. Then, $x \mathrm{GnP}$ was incorporated into the PLA/PEG blend. The prepared nanocomposites exhibited a significant improvement in tensile properties at a low xGnP loading. The tensile properties demonstrated the addition of $0.3 \mathrm{wt} \%$ of $\mathrm{xGnP}$ led to an increase of up to $32.7 \%, 69.5 \%$ and $21.9 \%$ in tensile strength, tensile modulus and elongation at break of the nanocomposites respectively, compared to PLA/PEG blend. X-ray diffraction (XRD) patterns showed the presence of a peak around $26.5^{\circ}$ in PLA/PEG/xGnP nanocomposites which corresponds to the characteristic peak of xGnP. The nanocomposites also shows enhanced thermal stability compared with PLA/PEG blend in thermogravimetry analysis (TGA). The enhancement to some extent of the tensile properties of the PLA/PEG/xGnP nanocomposites can be ascribed to the homogeneous dispersion and orientation of the $\mathrm{xGnP}$ nanoplatelets in the polymer matrix and strong interfacial interaction between both components. The scanning electron microscopy (SEM) image of PLA/PEG/0.3 wt $\% \mathrm{xGnP}$ displays good uniformity and more
\end{abstract}


homogenous morphology. Good uniformity of composites indicates a good degree of dispersion of the $\mathrm{xGnp}$ and therefore results in good tensile and thermal properties.

Keywords: graphene nanoplatelets; reinforcement; filler

\section{Introduction}

Polymer nanocomposites based on graphene have attracted tremendous attention in recent years from both the scientific and academic communities as a result of the substantial property enhancements obtained from relatively low nanofiller loadings [1-3]. Various nano-reinforcement fillers, such as layered silicate clay, carbon nanotubes and layered double hydroxide are being developed and extensively studied in the field of polymer nanocomposites [4]. However, the discovery of new nano-material graphene by Andre Geim in 2004 [5] excited worldwide interest among researchers.

Graphene, which is fabricated from natural graphite, a one-atom-thick two dimensional honeycomb layer of sp2 bonded carbon, can be used as a potential alternative nano-reinforcement to both clay and carbon nanotubes. Graphene combines layered structure of clays with superior mechanical and thermal properties of carbon nanotubes, which can provide excellent functional property enhancements [6]. Since graphite is the stiffest material found in nature, having a modulus several times higher than clay, and given its excellent strength, electrical and thermal conductivity, it ought to have similar properties to carbon-based nanomaterials [1]. Furthermore, graphene is much cheaper than either single-walled carbon nanotubes or multi-walled carbon nanotubes. Exfoliated graphene nanoplatelets (xGnP), multiple graphene layers stacked to form platelets, were developed by a cost effective method as mentioned by Fukushima [7]. Researchers such as Kalaitzidou et al. [8], Miloaga et al. [9] and Pinto et al. [10] have investigated the application of $\mathrm{xGnP}$ as a reinforcement filler with different polymers.

Poly(lactic acid) (PLA) is one of the most frequently used biodegradable polymers, especially in packaging applications due to its high strength, high modulus, good transparency, processability and biocompatibility. However, PLA also has the drawbacks of inherent brittleness and poor toughness, which impede its wide application. Many efforts have been carried out to improve the properties of PLA so as to compete with the low cost and flexible commodity polymers. These attempts include blending PLA with other polymers, modifying PLA with plasticizers, or blending with inorganic nano-fillers.

Polyethylene glycols (PEG), also known as macrogols, are liquid or solid polymers of the general formula $\mathrm{H}\left(\mathrm{OCH}_{2} \mathrm{CH}_{2}\right)_{n} \cdot \mathrm{OH}$. It has been found that $\mathrm{PEG}$ shows great promise as a plasticizing agent for PLA as it gives a large increase in elongation at break [11-16]. However, this is accompanied by a dramatic loss in tensile strength and tensile modulus. A recent study by Chieng and co-workers employed low molecular weight PEG (PEG-200) as a plasticizer to improve the ductility of PLA [17]. PEG acts as plasticizer in terms of reducing glass transition temperature $\left(T_{\mathrm{g}}\right)$ of PLA. The tensile properties demonstrated that the addition of PEG-200 led to an increase of elongation at break $(>7000 \%)$, but a decrease of both tensile strength and tensile modulus. However, PLA/PEG blend was not stable and the attractive properties are lost over time because of phase separation at ambient temperatures leading to the formation of PLA-rich and PEG-rich phases [18]. 
In this study, graphene nanoplatelets (xGnP) were investigated as nano-reinforcement filler in PLA/PEG blend by the melt blending technique. Significant improvements in tensile strength, tensile modulus as well as elongation at break were observed when $\mathrm{xGnP}$ was incorporated as reinforcement filler into PLA/PEG blend. The reason for this is that, due to the nano-scale dispersion, even with very low level of nano-reinforcement filler which results in high aspect ratio and surface area, the reinforcement efficiency of the composites can be significantly better than the conventional fillers.

\section{Experimental Section}

\subsection{Materials}

Poly(lactic acid) resin, commercial grade 4042D, was supplied by NatureWorks ${ }^{\circledR}$ LCC (Minnetonka, MN, USA). Low molecular weight Poly(ethylene glycol) (Mn = $200 \mathrm{~g} / \mathrm{mol}$ ) purchased from Acros Organics (Fair Law, NJ, USA). Their chemical structures are shown in Figure 1. Graphene nanoplatelets, trade name $\mathrm{xGnP}^{\circledR}$, Grade $\mathrm{M}$, was supplied by XG sciences Inc. (Lansing, MI, USA). Each particle consists of several sheet of graphene with an average thickness of approximately 6-8 nanometers, average diameter of 15 microns.

Figure 1. Chemical structures of (a) PLA and (b) PEG.

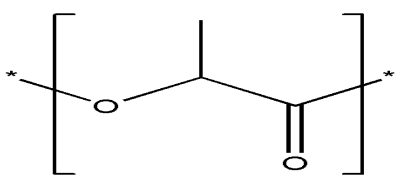

(a)

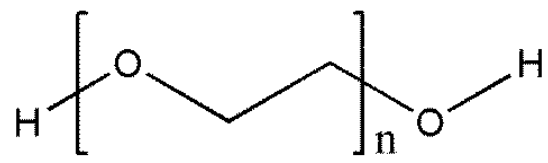

(b)

\subsection{Preparation of $P L A / P E G / x G n P$ Nanocomposites}

In order to prevent any potential hydrolytic degradation of the PLA during the melt processing, PLA was dried in an oven at $60{ }^{\circ} \mathrm{C}$ for $12 \mathrm{~h}$ before processing. The PLA/PEG/xGnP nanocomposites were prepared by melt blending technique using Brabender internal mixer with $25 \mathrm{rpm}$ of the rotor speed, at $160{ }^{\circ} \mathrm{C}$ for $10 \mathrm{~min}$. The PEG was used as plasticizer to PLA. The weight ratio of PLA to PEG was kept constant at 90/10. The $\mathrm{xGnP}$ content was varied between $0.1 \mathrm{wt} \%$ and $1.0 \mathrm{wt} \%$. The composites obtained were then molded into sheets of $1 \mathrm{~mm}$ in thickness by hot pressing at $160{ }^{\circ} \mathrm{C}$ for $10 \mathrm{~min}$ with pressure of $110 \mathrm{~kg} / \mathrm{cm}^{2}$, followed by cooling to room temperature. The sheets were used for further characterization.

\subsection{Characterizations}

\subsubsection{Tensile Properties Measurement}

Tensile properties test were carried out by using Instron 4302 series IX (Buckinghamshire, UK). The samples were cut into dumbbell shape follow ASTM D638 (type V) standard [19]. A load of $1.0 \mathrm{kN}$ was applied at constant crosshead speed of $10 \mathrm{~mm} / \mathrm{min}$ at room temperature. Tensile strength, tensile modulus and elongation at break were evaluated from the stress-strain data. Each sample included seven tested replicates to obtain a reliable mean and standard deviation. 


\subsubsection{X-ray Diffraction (XRD)}

X-ray diffraction measurement was carried out by using a Shimadzu XRD 6000 X-ray (Tokyo, Japan) diffractometer with $\mathrm{CuK}_{\alpha}$ radiation $(\lambda=1.542 \AA)$ operated at $30 \mathrm{kV}$ and $30 \mathrm{~mA}$. Data were recorded in $2 \theta$ range of $2^{\circ}-10^{\circ}$ at the scan rate of $2 \% \mathrm{~min}$.

\subsubsection{Fourier Transform Infrared (FTIR)}

FTIR spectra were recorded using Fourier Transform Infrared Spectrometer Perkin Elmer BX (Waltham, MA, USA) equipped with a universal attenuated total reflectance. The spectra were recorded between 4000 and $280 \mathrm{~cm}^{-1}$ frequency ranges.

\subsubsection{Differential Scanning Calorimetry (DSC)}

DSC analysis was performed by Perkin Elmer JADE DSC (Waltham, MA, USA) to study the nonisothermal crystallization kinetics. The DCS procedure was consisting of three steps. At the first step, the films were heated from 30 to $180{ }^{\circ} \mathrm{C}$ with a heating rate of $10{ }^{\circ} \mathrm{C} / \mathrm{min}$, then they were held at this temperature for $5 \mathrm{~min}$ to eliminate the thermal history, and they were cooled to $30{ }^{\circ} \mathrm{C}$ at cooling rate of $10{ }^{\circ} \mathrm{C} / \mathrm{min}$ and held at $30{ }^{\circ} \mathrm{C}$ for $5 \mathrm{~min}$. In the last step, they were reheated to $180{ }^{\circ} \mathrm{C}$ at a heating rate of $10^{\circ} \mathrm{C}$.

\subsubsection{Thermogravimetric Analysis (TGA)}

TGA was carried out using a Perkin Elmer Pyris 7 TGA analyzer (Waltham, MA, USA) with scan range from $35^{\circ}$ to $800^{\circ}$ at a constant heating rate of $10{ }^{\circ} \mathrm{C} / \mathrm{min}$ and continuous nitrogen flow. The thermal degradation temperature taking into account were the temperature at onset $\left(T_{\text {onset }}\right)$ and the temperature of maximum weight loss $\left(T_{\max }\right)$.

\subsubsection{Scanning Electron Microscopy (SEM)}

The samples were submerged in liquid nitrogen and broken down. The morphology of fracture surfaces were studied under a JEOL SEM instrument JSM-6400 (Tokyo, Japan) at an accelerating voltage of $30 \mathrm{kV}$. The fractured surfaces were coated with a thin layer of gold prior to observation.

\section{Results and Discussion}

\subsection{X-ray Diffraction}

XRD patterns collected from the $\mathrm{xGnP}$ powder, PLA/PEG blend and PLA/PEG/xGnP nanocomposites are shown in the Figure 2. The diffraction pattern for the $\mathrm{xGnP}$ shows the graphite characteristic peak at $2 \theta=26.6^{\circ}(d=3.35 \AA)$. Slight broadening of the peak indicates the presence of platelets with different dimensions. As shown in Figure 2, the intensity of the graphite peak at $26.6^{\circ}$ increased with the weight percent of the $\mathrm{xGnP}$. No peak shift was observed. A broad amorphous peak from PLA was observed in PLA/PEG blend around $16.8^{\circ}$. This confirms the PLA has an amorphous microstructure. As the $\mathrm{xGnP}$ loading is increased, the intensity of the diffraction peak 
becomes stronger, confirming the increased crystallization in PLA/PEG at high xGnP loadings. The XRD results demonstrate the crystalline structure of PLA is slightly increased by the incorporation of $\mathrm{xGnP}$.

Figure 2. X-ray diffraction (XRD) patterns of graphene nanoplatelets (xGnP), PLA/PEG, and PLA/PEG nanocomposites.

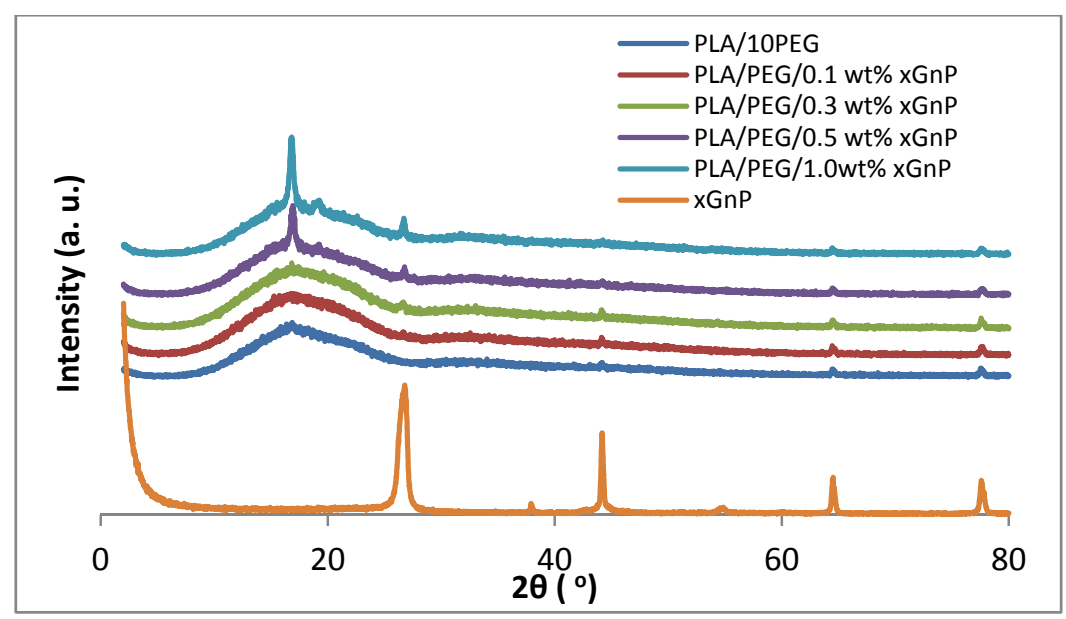

\subsection{Fourier-Transform Infrared}

Figure 3 shows FTIR spectra of pristine PLA, PEG, PLA/PEG blend and PLA/PEG nanocomposites. PLA shows characteristic stretching frequencies for $\mathrm{C}=\mathrm{O},-\mathrm{CH}_{3}$ asymmetric, $-\mathrm{CH}_{3}$ symmetric, and $\mathrm{C}-\mathrm{O}$, at 1746, 2995, 2946 and $1080 \mathrm{~cm}^{-1}$, respectively. Bending frequencies for $-\mathrm{CH}_{3}$ asymmetric and $-\mathrm{CH}_{3}$ symmetric have been identified at 1452 and $1361 \mathrm{~cm}^{-1}$, respectively. Meanwhile, a broad peak was observed at $3446 \mathrm{~cm}^{-1}$ for PEG, which corresponds to terminal hydroxyl group. PLA/PEG and PLA/PEG nanocomposite shows almost same absorption peaks as pristine PLA. This means that there is no new bond formed or strong chemical interaction occurring within the blend and nanocomposites.

Figure 3. Fourier transform infrared (FTIR) spectra of PLA, PEG, PLA/PEG blend and PLA/PEG/xGnP nanocomposite.

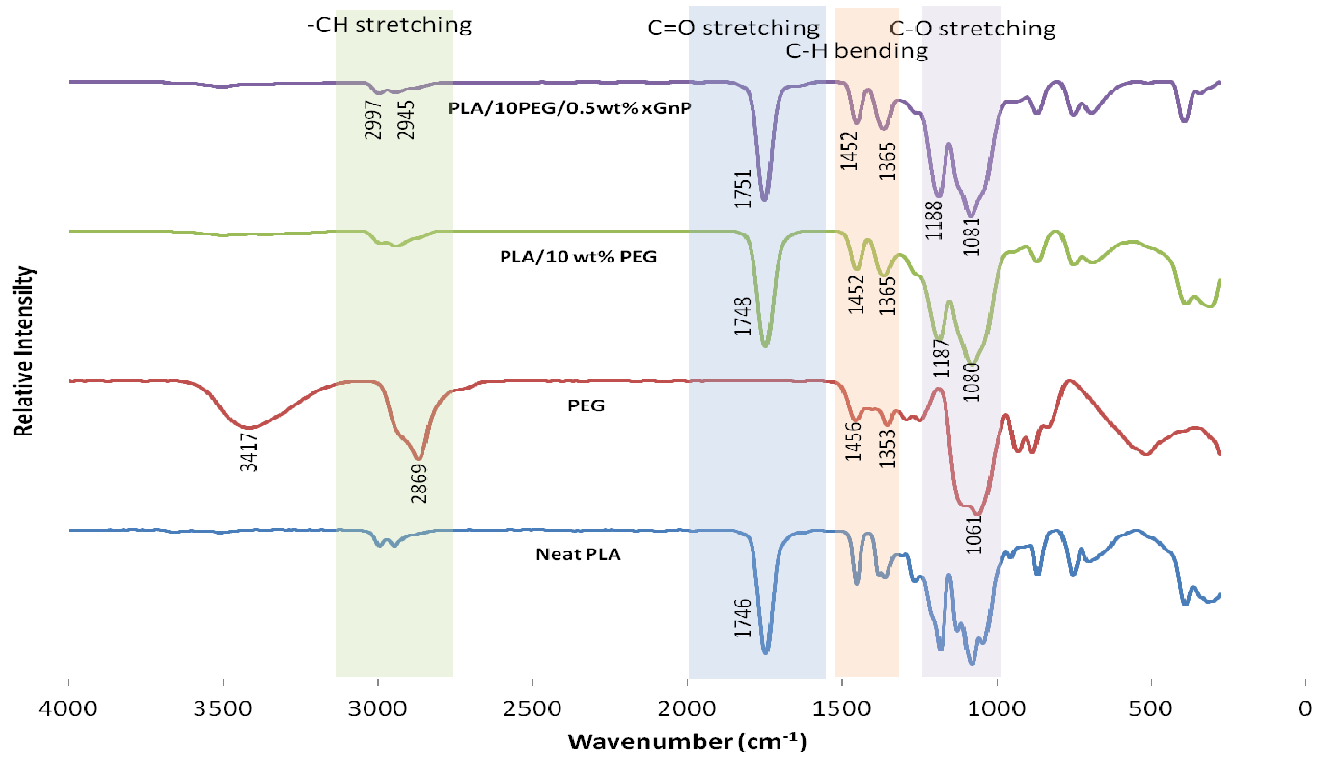




\subsection{Mechanical Properties}

For tensile testing, the properties most frequently evaluated are the elongation at break $\left(\varepsilon_{\mathrm{b}}\right)$, tensile strength at break $\left(\sigma_{\mathrm{b}}\right)$, and tensile modulus (E). For PLA, a typical goal is to increase the elongation at break and tensile toughness without adversely affecting the tensile strength and tensile modulus.

The tensile properties of PLA, PLA/PEG and PLA/PEG/xGnP nanocomposite were examined at room temperature, as shown in Figure 4, which displays stress-strain curves. The neat PLA was typically rigid and brittle. It had high tensile modulus as well as tensile strength, but with very limited elongation at break. After the addition of plasticizer PEG, the tensile strength and modulus of the PLA decreased, whereas the elongation at break significantly increased. An increase of elongation at break means that the brittleness of PLA decreased since the elongation at break and brittleness are inversely proportional.

Figure 4. Stress-strain curves of PLA, PLA/PEG, and PLA/PEG/xGnP nanocomposite.

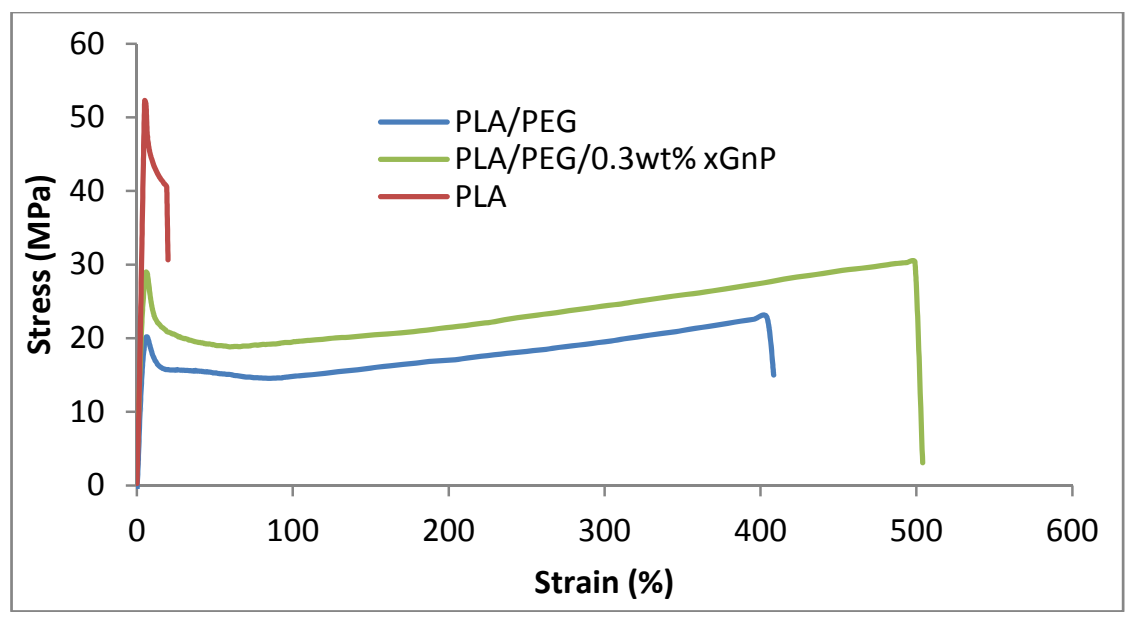

The effect of $x G n P$ loading on PLA/PEG blend is depicted in Figure 5. The aim of incorporating $\mathrm{xGnP}$ into the blend is to improve its mechanical properties. Tensile strength of PLA/PEG increases as $\mathrm{xGnP}$ loading increases and attains the highest value $(30 \mathrm{MPa})$ at $0.3 \mathrm{wt} \% \mathrm{xGnP}$ loading. Further increase of $\mathrm{xGnP}$ loading decreases the tensile strength. The decrement in tensile strength for the $\mathrm{xGnP}$ loading above $0.3 \mathrm{wt} \%$ could be attributed to intrinsic van der Waals interaction of $\mathrm{xGnPs}$ which leads to inevitable aggregation of the $\mathrm{xGnP}$ in high content, and thus prevents efficient load transfer to the polymer matrix. In the meantime, tensile modulus increases from $424 \mathrm{MPa}$ for PLA/PEG blend to $780 \mathrm{MPa}$ for the nanocomposite containing $0.1 \mathrm{wt} \% \mathrm{xGnP}$ as shown in Figure $5 \mathrm{~b}$. However, the tensile modulus does not differ significantly at all xGnP loadings. The enhancement to some extent of the tensile properties of the PLA/PEG/xGnP nanocomposites can be ascribed to the homogeneous dispersion and orientation of the $\mathrm{xGnP}$ nanoplatelets in the polymer matrix and strong interfacial interaction between both components.

Figure $5 \mathrm{c}$ shows the elongation at break of PLA/PEG/xGnP nanocomposites. PLA/PEG blend shows elongation at break of $413 \%$. It increases with the addition of $\mathrm{xGnP}$. The highest elongation at break (503\%) is observed from PLA/PEG with $0.3 \mathrm{wt} \% \mathrm{xGnP}$ loading. Further addition of xGnP causes the decrease of elongation at break, which made the blend more brittle. The reason for this may be attributed to a large aspect ratio of the rigid $\mathrm{xGnP}$ filler and the interaction between $\mathrm{xGnP}$ and the matrix, which restricts the movement of the polymer chains [20]. 
Figure 5. (a) Tensile strength; (b) tensile modulus; and (c) elongation at break of $\mathrm{PLA} / \mathrm{PEG} / \mathrm{xGnP}$ nanocomposites as a function of $\mathrm{xGnP}$ loading. (Confidence Interval C.I. $95 \%)$.
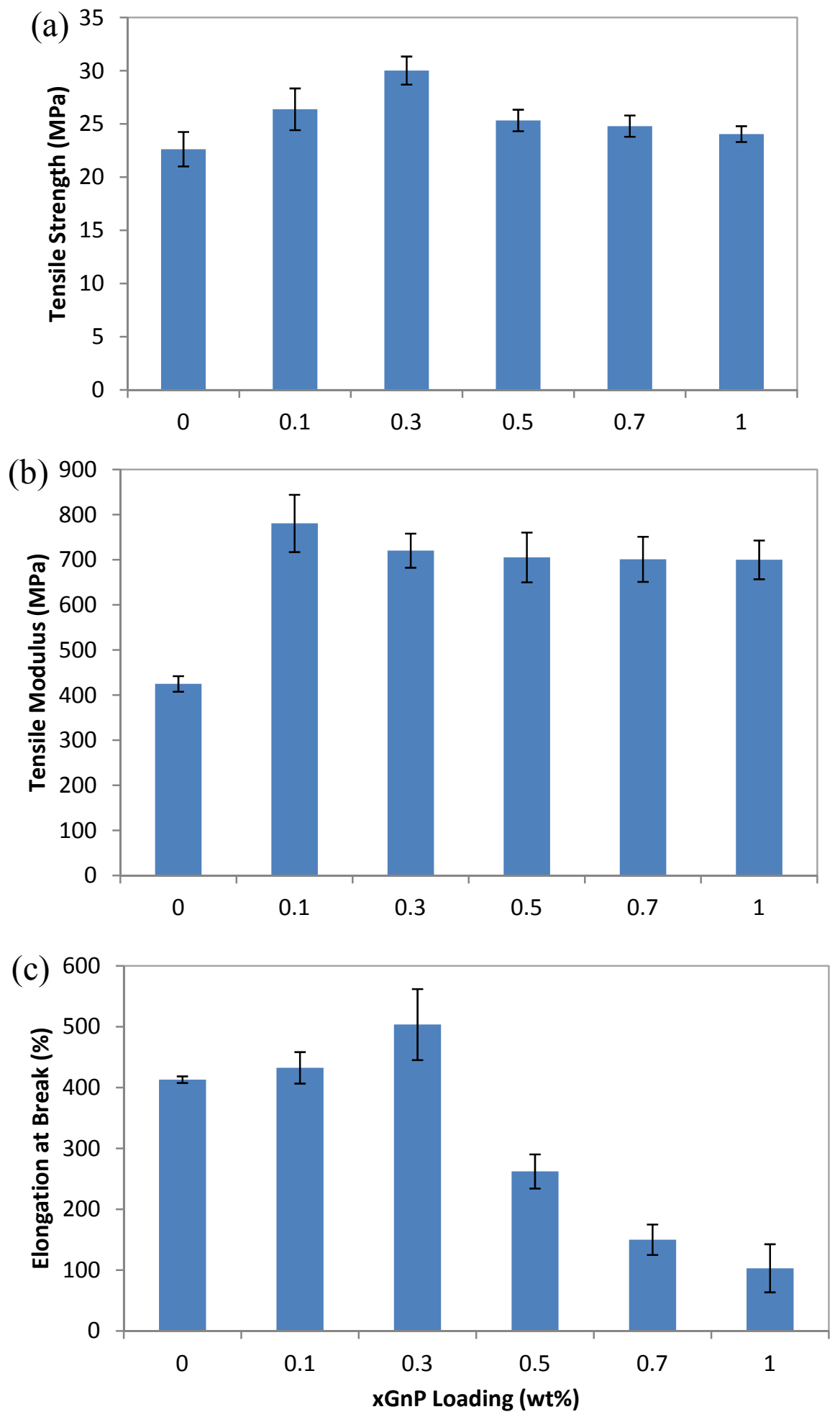

\subsection{Thermal Properties}

Since PLA is a semicrystalline polymer, its mechanical properties should strongly depend on its crystallinity. Therefore, to confirm the influence of incorporating xGnP into PLA on the mechanical 
enhancement of the composites, DSC is employed to measure the crystallinity difference between PLA/PEG blend and PLA/PEG/xGnP nanocomposites. For PLA/PEG blend and its nanocomposites, the DSC thermograms are shown in Figure 6. The melting curves have similar peaks, and the melting points of PLA/PEG blend and the nanocomposites are almost same. The crystallinity $\left(X_{\mathrm{c}}\right)$ in all samples is calculated as follows:

$$
X_{C}(\%)=\frac{\Delta H_{\mathrm{m}}-\Delta H_{c c} / \Phi_{\mathrm{PLA}}}{\Delta H_{m}^{o}} \times 100 \%
$$

where $\Delta H_{\mathrm{m}}$ is the measured heat of fusion, $\Delta H_{c c}$ is the heat of cold crystallization, $\Phi_{\mathrm{PLA}}$ is the PLA content in the composites and $\Delta H_{m}^{o}$ is melting enthalpy of the $100 \%$ PLA (93.6 J/g). As shown in Table 1, the crystallinity of PLA/PEG nanocomposites is increased after adding the $\mathrm{xGnP}$, which corresponds well with the XRD results. However, the change of PLA crystallinity is so slight that it cannot induce a significant impact on the mechanical properties of the composites. Therefore, the significant reinforcement of the strength and modulus for PLA/PEG nanocomposites can be mostly attributed to the homogeneous dispersion of $\mathrm{xGnP}$ in the polymer matrix and strong interactions between both components [21].

Figure 6. Differential scanning calorimetry (DSC) thermograms of PLA/PEG at various $\mathrm{xGnP}$ contents.

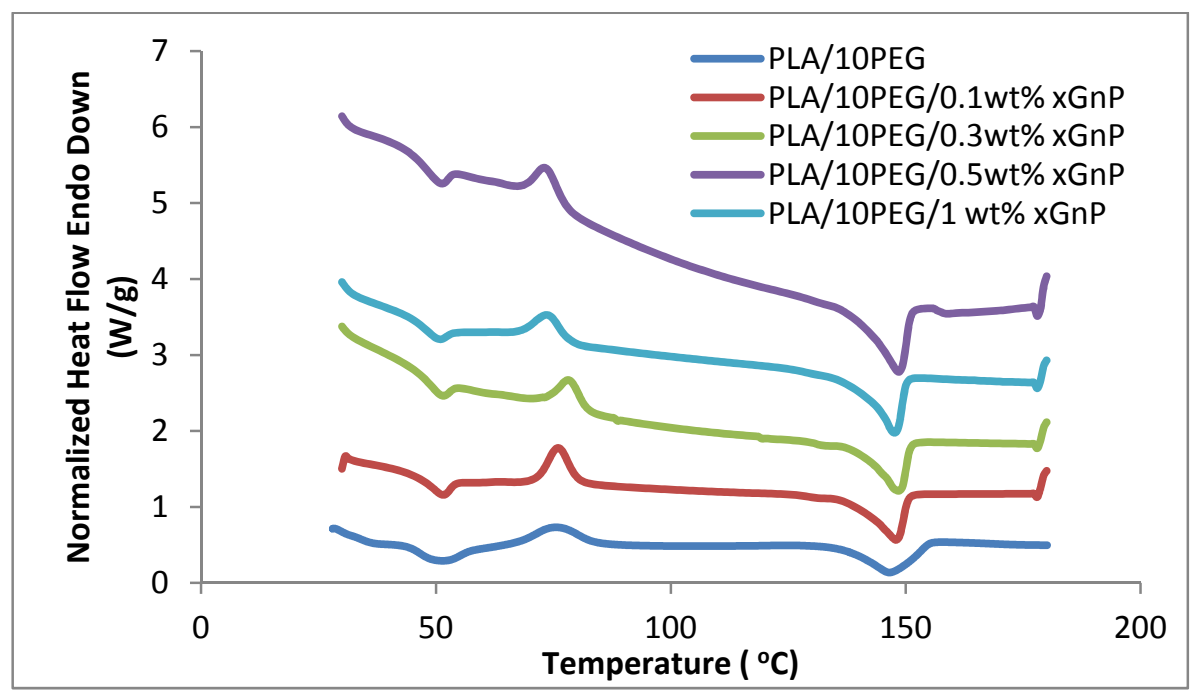

Table 1. Characteristic temperature and percentage of crystallinity of PLA/PEG and PLA/PEG/xGnP nanocomposites.

\begin{tabular}{ccccc}
\hline Samples & $\boldsymbol{T}_{\mathbf{g}}\left({ }^{\circ} \mathbf{C}\right)$ & $\boldsymbol{T}_{\mathbf{c c}}\left({ }^{\circ} \mathbf{C}\right)$ & $\boldsymbol{T}_{\mathbf{m}}\left({ }^{\circ} \mathbf{C}\right)$ & $\boldsymbol{X}_{\mathbf{c}}(\mathbf{\%})$ \\
\hline PLA/10PEG & 51.63 & 74.30 & 146.48 & 49.43 \\
PLA/10 PEG/0.1 wt\% xGnP & 51.26 & 75.98 & 147.82 & 50.95 \\
PLA/10 PEG/0.3 wt\% xGnP & 51.26 & 78.26 & 148.25 & 51.77 \\
PLA/10 PEG/0.5 wt\% xGnP & 50.79 & 73.29 & 148.27 & 53.91 \\
PLA/10 PEG/1 wt\% xGnP & 50.45 & 73.80 & 147.30 & 54.61 \\
\hline
\end{tabular}

Upon heating, enhanced molecular mobility can give rise to crystallization of PLA, which is termed as cold crystallization. It is indicated that cold crystallization temperature is first increased and then 
decreased with respect to $\mathrm{xGnP}$ loadings. As shown in Table 1, the cold crystallization temperature of PLA/PEG is about $74.30{ }^{\circ} \mathrm{C}$ and shift to around $75.98,78.26,73.29$ and $73.80{ }^{\circ} \mathrm{C}$ for $0.1,0.3,0.5$ and $1.0 \mathrm{wt} \% \mathrm{xGnP}$, respectively. The above change of cold crystallization behavior in the PLA/PEG/xGnP nanocomposites results from the combined effects of nucleation and diffusion controlled growth processes. On the other hand, the nucleation ability of $\mathrm{xGnP}$ toward PLA matrix gives rise to the decreasing of cold crystallization temperature at higher xGnP loadings $[22,23]$.

As an effective plasticizer for PLA, addition of PEG does enhance the molecular motions, manifested by the significant decrease of glass transition temperature in the plasticized PLA as reported in previous study [17]. Moreover, in the plasticized PLA adding xGnP further decreases glass transition temperature, whereas its loading is and beyond $1 \mathrm{wt} \%$. However, the change in glass transition temperature of $\mathrm{PLA} / \mathrm{PEG} / \mathrm{xGnP}$ nanocomposites is not significant with respect to that of plasticized PLA itself.

Thermal properties of pristine PLA/PEG blend and its nanocomposites were investigated by thermogravimetry analysis (TGA). The integral (TGA) and derivative (DTG) thermogravimetric curves provide information about the nature and extent of degradation of the polymeric materials. The TGA and DTG thermograms of PLA/PEG blend and nanocomposites are given in Figure 7. A detailed evaluation of the thermograms is presented in Table 2.

Figure 7. Effect of $x \mathrm{GnP}$ on thermal stability of PLA/PEG (a) thermogravimetry analysis (TGA) and (b) derivative thermogravimetric (DTG) curves.
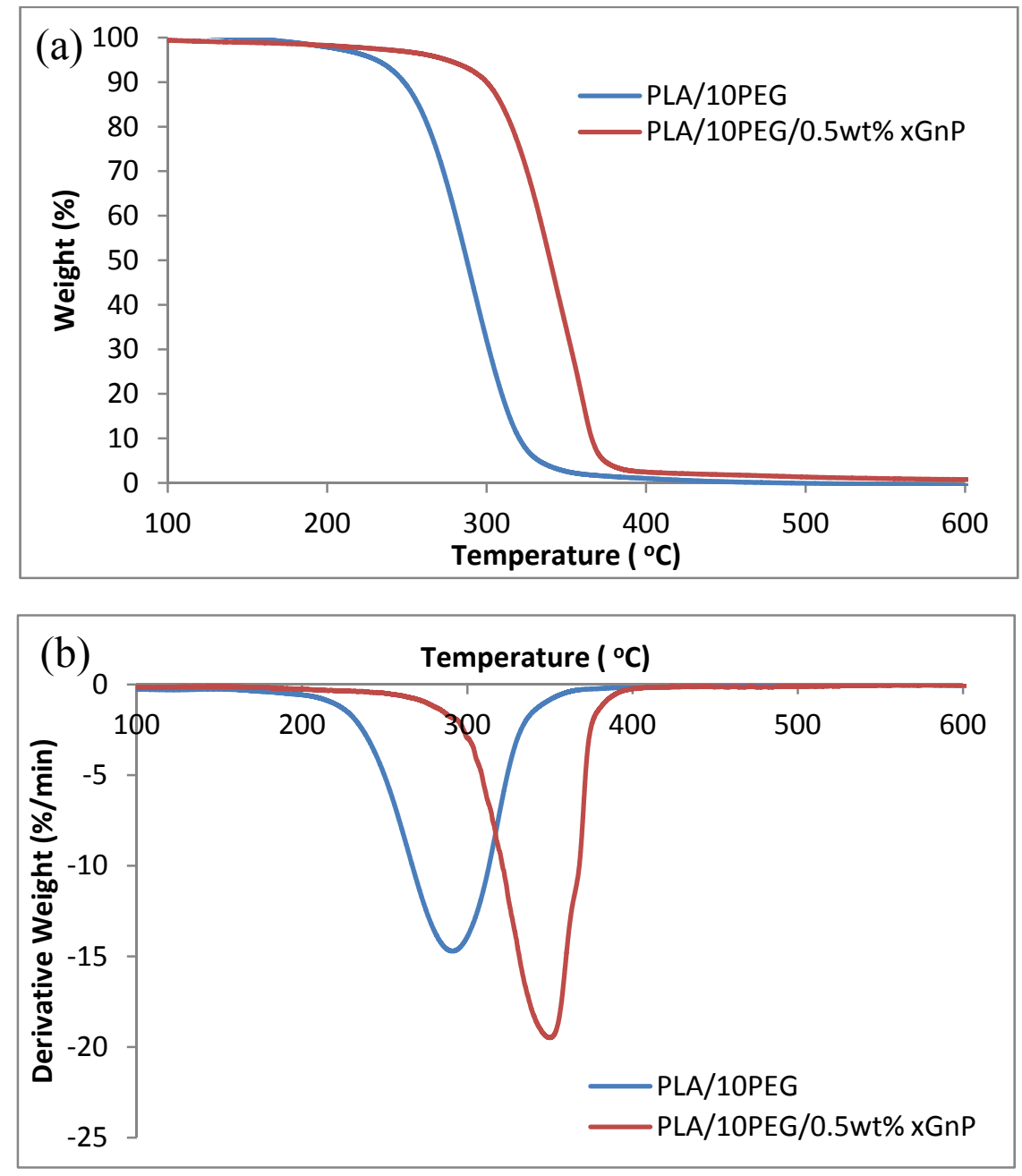
Table 2. Thermal degradation temperature of PLA/PEG and PLA/PEG/xGnP nanocomposite.

\begin{tabular}{cccc}
\hline Samples & $\boldsymbol{T}_{\text {onset }}\left({ }^{\circ} \mathbf{C}\right)$ & $\boldsymbol{T}_{\max }\left({ }^{\circ} \mathbf{C}\right)$ & $\boldsymbol{T}_{\mathbf{5 0}}\left({ }^{\circ} \mathbf{C}\right)$ \\
\hline PLA/PEG & 194.5 & 291.0 & 285.7 \\
PLA/PEG/0.5 wt $\%$ xGnP & 250.4 & 344.0 & 339.8 \\
\hline
\end{tabular}

The decomposition onset temperature $\left(T_{\text {onset }}\right)$ and maximum decomposition temperature $\left(T_{\max }\right)$ as well as the decomposition temperature at $50 \%$ weight loss $\left(T_{50}\right)$ of PLA/PEG/xGnP nanocomposite shift to higher temperatures when $\mathrm{xGnP}$ is added. For example, a shift from 194.5 to $250.4{ }^{\circ} \mathrm{C}$ and from 291.0 to $344.0{ }^{\circ} \mathrm{C}$ is observed for the decomposition onset temperature and the maximum decomposition temperature of the sample PLA/PEG/0.3 wt $\% \mathrm{xGnP}$, respectively. The improvement in thermal stability of nanocomposites attributed to the $\mathrm{xGnP}$ nanofiller itself possessed high thermal stability. When xGnP was added into polymer matrices it will enhance the overall material's thermal stability. Moreover, its layer structure exhibited a greater barrier effect to hinder the evaporation of the volatile degradation products generated in thermal decomposition of the nanocomposites. Furthermore, the formation of tortuous path with exfoliated $\mathrm{xGnP}$ also inhibited the passage of volatile degradation products, hence enhancing the thermal stability of the $\mathrm{xGnP}$ containing nanocomposites.

\subsection{Morphology}

Micrographs of (a) PLA/PEG blend and (b) PLA/PEG/0.3 wt\% xGnP were shown in the Figure 8. Both reveal plastic deformation and few long threads of a deformed material are discernible on the fracture surface of the sample. This shows that the PLA/PEG/xGnP gained the ability to plastic deformation leading to about $21.9 \%$ increment in elongation at break in the case of $0.3 \mathrm{wt} \% \mathrm{xGnP}$ content. The SEM image of PLA/PEG/0.3 wt $\%$ xGnP displays good uniformity and more homogenous morphology. Good uniformity of composites indicates good degree of dispersion of the $\mathrm{xGnp}$ and therefore results in good tensile and thermal properties.

Figure 8. SEM images of (a) PLA/PEG; and (b) PLA/PEG/0.3 wt \% xGNP nanocomposite.

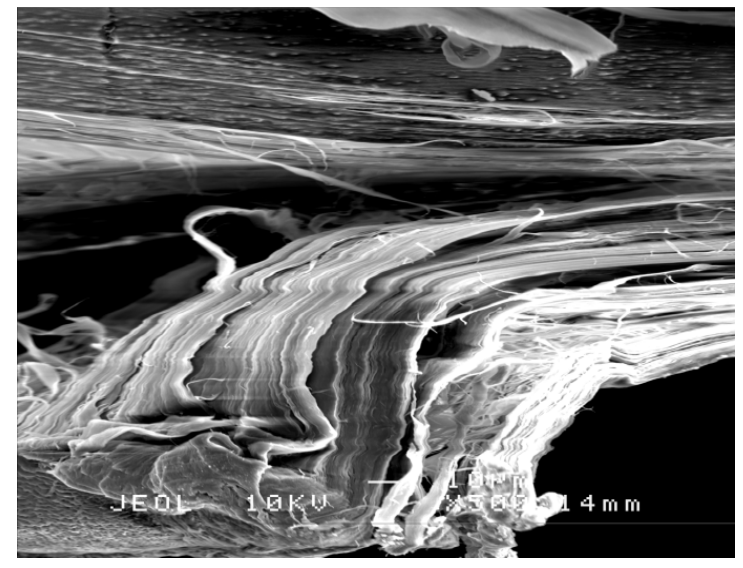

(a)

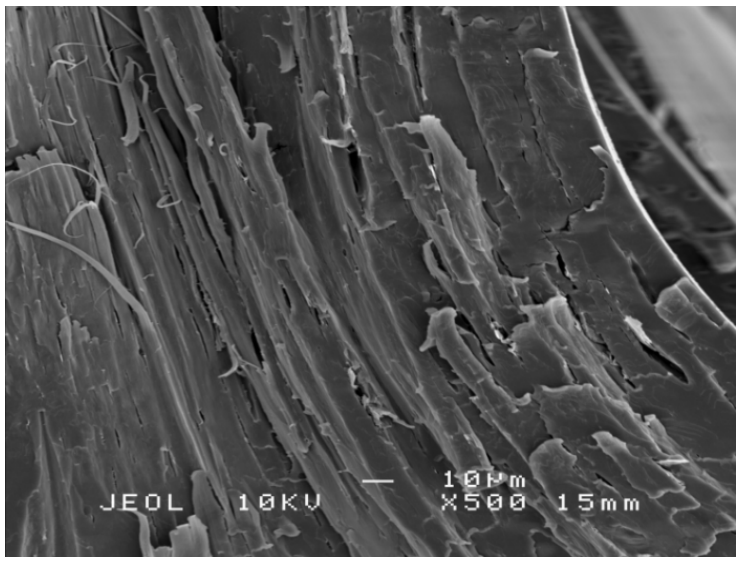

(b) 


\section{Conclusions}

$\mathrm{xGnP}$ was effective in achieving an improved tensile properties for PLA/PEG blend. Tensile tests show very significant improvements with the addition of very small amount of $\mathrm{xGnP}$. An optimum loading is identified of about $0.3 \mathrm{wt} \% \mathrm{xGnP}$, indicating that, for higher $\mathrm{xGnP}$ additions, agglomeration effects overcome the reinforcement benefits. With addition of $\mathrm{xGnP}$, it overcomes the problem of phase separation or aging in PLA/PEG blend. The addition of $\mathrm{xGnP}$ will prevent the diffusion of short molecular chains of PEG to the surface, which will lead to the loss of properties. Further investigation for understanding the interaction between polymer and $\mathrm{xGnP}$ is needed. An ability to further disperse the exfoliated platelets is an important next step shared with many nano-reinforcements.

\section{Acknowledgments}

The authors would like to thank the Exploratory Research Grant Scheme (ERGS) from Ministry of Higher Education (MOHE), Malaysia for their financial support.

\section{Conflicts of Interest}

The authors declare no conflict of interest.

\section{References}

1. Kuila, T.; Bhadra, S.; Yao, D.; Kim, N.H.; Bose, S.; Lee, J.H. Recent advances in graphene based polymer composites. Prog. Polym. Sci. 2010, 35, 1350-1375.

2. Singh, V.; Joung, D.; Zhai, L.; Das, S.; Khondaker, S.I.; Seal, S. Graphene based materials: Past, present and future. Prog. Mater. Sci. 2011, 56, 1178-1271.

3. Salavagione, H.J.; Martínez, G.; Ellis, G. Recent advances in the covalent modification of graphene with polymers. Macromol. Rapid Commun. 2011, 32, 1771-1789.

4. Chiang, M.-F.; Wu, T.-M. Synthesis and characterization of biodegradable poly(l-lactide)/layered double hydroxide nanocomposites. Compos. Sci. Technol. 2010, 70, 110-115.

5. Geim, A.K. Graphene: Status and prospects. Science 2009, 324, 1530-1534.

6. Kalaitzidou, K.; Fukushima, H.; Drzal, L.T. Mechanical properties and morphological characterization of exfoliated graphite-polypropylene nanocomposites. Compos. Part A Appl. Sci. Manuf. 2007, 38, 1675-1682.

7. Fukushima, H. Graphite nanoreinforcements in polymer nanocomposites. Ph.D. Thesis, 3092144, Michigan State University, Michigan, MI, USA, 2003.

8. Kalaitzidou, K.; Fukushima, H.; Drzal, L.T. A new compounding method for exfoliated graphite-polypropylene nanocomposites with enhanced flexural properties and lower percolation threshold. Compos. Sci. Technol. 2007, 67, 2045-2051.

9. Miloaga, D.G.; Hosein, H.-A.A.; Misra, M.; Drzal, L.T. Crystallization of poly(3-hydroxybutyrate) by exfoliated graphite nanoplatelets. J. Appl. Polym. Sci. 2007, 106, 2548-2558.

10. Pinto, A.M.; Cabral, J.; Tanaka, D.A.P.; Mendes, A.M.; Magalhães, F.D. Effect of incorporation of graphene oxide and graphene nanoplatelets on mechanical and gas permeability properties of poly(lactic acid) films. Polym. Int. 2013, 62, 33-40. 
11. Gumus, S.; Ozkoc, G.; Aytac, A. Plasticized and unplasticized PLA/organoclay nanocomposites: Short- and long-term thermal properties, morphology, and nonisothermal crystallization behavior. J. Appl. Polym. Sci. 2011, 123, 2837-2848.

12. Pluta, M.; Paul, M.-A.; Alexandre, M.; Dubois, P. Plasticized polylactide/clay nanocomposites. I. The role of filler content and its surface organo-modification on the physico-chemical properties. J. Polym. Sci. Part B Polym. Phys. 2006, 44, 299-311.

13. Sungsanit, K.; Kao, N.; Bhattacharya, S.N. Properties of linear poly(lactic acid)/polyethylene glycol blends. Polym. Eng. Sci. 2012, 52, 108-116.

14. Hu, Y.; Hu, Y.S.; Topolkaraev, V.; Hiltner, A.; Baer, E. Crystallization and phase separation in blends of high stereoregular poly(lactide) with poly(ethylene glycol). Polymer 2003, 44, 5681-5689.

15. Gui, Z.; Xu, Y.; Gao, Y.; Lu, C.; Cheng, S. Novel polyethylene glycol-based polyester-toughened polylactide. Mater. Lett. 2012, 71, 63-65.

16. Baiardo, M.; Frisoni, G.; Scandola, M.; Rimelen, M.; Lips, D.; Ruffieux, K.; Wintermantel, E. Thermal and mechanical properties of plasticized poly(L-lactic acid). J. Appl. Polym. Sci. 2003, 90, 1731-1738.

17. Chieng, B.W.; Ibrahim, N.A.; Wan Yunus, W.M.Z.; Hussein, M.Z. Plasticized poly(lactic acid) with low molecular weight poly(ethylene glycol): Mechanical, thermal, and morphology properties. J. Appl. Polym. Sci. 2013, 130, 4576-4580.

18. Hu, Y.; Hu, Y.S.; Topolkaraev, V.; Hiltner, A.; Baer, E. Aging of poly(lactide)/poly(ethylene glycol) blends. Part 2. Poly(lactide) with high stereoregularity. Polymer 2003, 44, 5711-5720.

19. American Society for Testing and Materials. Standard Test Method for Tensile Properties of Plastics; ASTM D638-02a; ASTM International: West Conshohocken, PA, USA, 2003.

20. Zhao, X.; Zhang, Q.; Chen, D.; Lu, P. Enhanced mechanical properties of graphene-based poly(vinyl alcohol) composites. Macromolecules 2010, 43, 2357-2363.

21. Xu, Y.; Hong, W.; Bai, H.; Li, C.; Shi, G. Strong and ductile poly(vinyl alcohol)/graphene oxide composite films with a layered structure. Carbon 2009, 47, 3538-3543.

22. Wang, H.; Qiu, Z. Crystallization kinetics and morphology of biodegradable poly(l-lactic acid)/graphene oxide nanocomposites: Influences of graphene oxide loading and crystallization temperature. Thermochim. Acta 2012, 527, 40-46.

23. Xu, H.-S.; Dai, X.J.; Lamb, P.R.; Li, Z.-M. Poly(L-lactide) crystallization induced by multiwall carbon nanotubes at very low loading. J. Polym. Sci. Part B Polym. Phys. 2009, 47, 2341-2352.

(C) 2013 by the authors; licensee MDPI, Basel, Switzerland. This article is an open access article distributed under the terms and conditions of the Creative Commons Attribution license (http://creativecommons.org/licenses/by/3.0/). 